\title{
Computer-mediated communication and interpersonal communication in social media Twitter among adolescents
}

Novianto Yudha Laksana

Department Communication, Faculty of Social Science,

Universitas Negeri Yogyakarta, Indonesia

Email: laksananyudha@uny.ac.id

\author{
Ahda Fadhilah \\ Department Communication, Faculty of Social Science Education, \\ Universitas Pendidikan Indonesia, Indonesia \\ Email:ahda@upi.edu
}

\begin{abstract}
Interactions that occur on social media through computer-mediated communication can form an interpersonal relationship between users. Based on Twitter data, $83 \%$ of Indonesian millennial users consider Twitter as a trusted source for access to product information. This study aims to gain the meaning of computer-mediated communication in the birth of interpersonal relationships between Twitter users among adolescents. This research method uses a qualitative approach through participant observation, in-depth interviews, and library studies. The study subjects were ten Twitter users with an educational background of high school students, which was determined based on purposive sampling techniques. The results revealed that on social media Twitter, interactions are generally made by teenagers commenting on each other's tweets about personal issues or life complaints. If there is a
\end{abstract}


frequency match, there will be a familiar feeling. The intense process through direct message channels makes communication feel more intimate and makes the relationship even tighter among users.

Keywords: Computer-Mediated Communication, Kauthentication Interpersonal, Twitter.

\section{Introduction}

The development of technology that is increasingly sophisticated makes many human activities affected by it. Starting from the economic sector, education, politics, and health, everything has been affected by the rapid development of technology. The presence of this new technology also has an impact on traditional media. A new term is new media (new media), whose use is very relevant to computers and the Internet. Although new media is limited to the Internet in its development, the Internet is the most dominant tool or media in new media (Situmorang, 1991). Because of its convenience, now every individual can enjoy new media anytime and anywhere. Its usefulness also varies, ranging from finding information, sharing information, expressing yourself through writing or other forms to interacting with others in cyberspace and making friends.

Interacting is one form of communication that changes with the development of technology. When interacting in the past, face-to-face takes a lot of time, effort, even money, or using letters, which is equally less efficient because the different distance makes receiving messages long. Now interaction can be done anywhere and anytime with the presence of new media, especially social media. Social media is a medium designed to facilitate social interactions that are interactive or two-way. Social media is based on internet technology that changes the dissemination of information from the previous one to many audiences (Saleh, 2018). Examples of social media that are being widely used right now are Twitter, Facebook, and Instagram. Through these platforms, communication networks on the Internet are used by humans as a place to form connections or interpersonal relationships. They can create a virtual community and share the same interests or likes there.

Social media is one form of communication mediated by computers or computer-mediated communication (CMC). Computer-Mediated Communication (CMC) is a new form of communication that can mark the era of technological 
and social change (Pratiwi, 2014). Interactions in cyberspace are free and can be done by anyone, and users must understand and can use social media services. The limitations on activities and interactions conducted on social media are also extensive. Even arguably, there are no particular restrictions. Users can state anything in their communication behavior, as all controls are in their hands thoroughly.

This also applies to interpersonal communication from users. Some experts state that relationships born of communication in cyberspace are not as strong as face-to-face relationships in real life when people can see and hear in person. They assessed that in cyber touch, to some context, interpersonal communication is lost. In interpersonal communication, there are four types of context included. First, relationship context that consists of the subject of relationships in transmission and expectations are mutual. Second, a context episode explains that all interpersonal communication participants are in the same event simultaneously. Third, self-concept context includes the image or self-image of the communication participants. Fourth, archetype context is an overview of truth (Suparno, 2012).

But if we examine more deeply, all the context of interpersonal communication is covered in computer-based communication. It is not as complete and fully running as face-to-face interpersonal communication, but social media also does not entirely abandon all aspects of this interpersonal communication. It is therefore not impossible to form more personal relationships based on interactions on social media. There are even times when relationships formed on social media feel more intimate than real-world relationships. The ties can see from the number of people who use matchmaking apps on the Internet. With the development of social media functions, their use is also increasing every day. Social media such as Instagram, WhatsApp, and Twitter are among the most popular services today, especially among young people. Nurhadi (2017), in his research on the model of social communication of adolescents through twitter media, explains the motive of using Twitter media that is due to the development of the social environment, the delivery and reception of short messages, and unlimited space and time. Now almost all teenagers have social media that he uses for a variety of things. They are starting from being self-existence, following trends, or making friends.

Based on what Nurhadi researched, researchers feel interested to conduct more specific research that focuses on interpersonal communication processes in social media among adolescents. Considering that youth are still in maturity 
and even in self-formation, it is essential to research. First, examine how computer-based interpersonal communication (technology) can occur. Second, look at how adolescents form intimate relationships from interactions that occur in cyberspace. This study will focus more on social media that is widely used among teenagers, namely Twitter social media.

\section{Literature Review}

\section{Computer-Mediated Communication}

Computer-Mediated Communication or, in English, ComputerMediated Communication, in a broad sense, can be interpreted as any form of communication mediated by digital technology (Littlejohn, 2009). Another definition, according to John December (Thurlow, 2004), Computer-Mediated Communication is a process of human communication through computers, involving people, being in a particular context, and engaging in the process of shaping media for various purposes. In short, it can use the definition according to Susan Herring, namely CMC is a communication that occurs between humans through computer instruments (Thurlow, 2004). From the three reports above, $\mathrm{CMC}$ can conclude that all communications conducted through computers, laptops, mobile phones, landlines, or the Internet are computermediated communications. A computer can mediate a touch or message if every aspect of it is converted into digital code, sent, and then translated by the recipient or listener. As the name implies, CMC has three central concepts, namely communication, mediated, and computer.

\section{Communication}

Communication is one of the concepts that is not limited by one definition because of its broad scope. Although communication is always done by humans in daily life, interpreting this concept is considered problematic. In $\mathrm{CMC}$ itself, this becomes interesting because, at the same time, communication feels like a novelty, but on the other hand, there is not much change or difference from regular communication with computer-mediated communication. However, what should be emphasized in this article the author will focus on human communication interpersonally and will not explain the scope of other communications such as intrapersonal communication or mass communication. According to Thurlaw (2004), communication has some properties that the first is dynamic communication. Communication is not just about delivering messages from the sender to the recipient. But it is better understood as a more 
active process. The statement does not have to be conveyed through the word but rather to its meaning and depends on the context of the conversation that is taking place. Secondly, communication is transactional. Communication, in general, is always interpreted as an exchange of messages between the sender and the recipient. Still, communication is more suitable is said to be a negotiation of meaning among people. This means that communication is a transaction between them. And third, communication is multifunctional. Intentionally or not, communication provides many functions and can play a role in many things at a time. Examples include influencing others' behavior, giving and seeking information, making friends, as entertainment, and so on. Finally, communication is multimodal. One way to communicate is through language, or what we often refer to as verbal communication. Verbal communication is always accompanied by other messages formed not from speech but other meaningful or nonverbal communication.

\section{Mediated}

According to the Chamber's Twenty-first Century Dictionary, the word mediate (mediation) means conveying or transmitting something or acting as a medium for something. Put mediation can be interpreted as the process of something being shared-be it a message, a feeling, a voice, and so on. In communication itself, a message is always channeled and depends on the context of meaning (Thurlaw, 2004). This means that this communication is mediated through interactions that we do daily with others. The method can be verbal communication through language and nonverbal communication, which is usually an action.

Communication channels or media are intermediaries in delivering information from communicators to others aimed at the efficiency of disseminating such information or messages. According to Suryanto (2015), communication media has several practical functions that facilitate the smooth delivery of information; efficiency that is to accelerate the delivery of information; concrete that helps accelerate the content of abstract messages; motivative that is to increase the spirit to communicate. These three functions will also certainly affect how communication occurs because it is directly related to humans' background, such as the level of education, age, and the culture in which they grow. In CMC itself, which is intended to mediate the message, it is technology to apply scientific knowledge in everyday life. 


\section{Computer}

Computer as a revolution left no area of life untouched in the present world. It is of tremendous help in all field of life (Jeleel, 201). Almost everything in life now involves computers or, for that matter, digital technology. They are starting from computers, laptops, mobile phones, tablets, cameras, and others. All of these tools are a form of computer mediation. In Computer-Mediated Communication, the concept of computers is more intended to be related to its facilities to facilitate human communication. How humans interact with others, make friends with fellow social media account users, create online communities, and form personal relationships with others in cyberspace.

\section{Interpersonal Communication}

Interpersonal communication talks about how people in a relationship talk to each other, why they choose the message they choose, and how that message affects relationships and individuals (Littlejohn \& Foss, 2009). Generally, many people define interpersonal communication as communication involving two people, whereas more than two people can do interpersonal communication. Or it makes the context of intimacy or intimacy an aspect to define interpersonal communication, but the reality is not like that. The best way to describe interpersonal communication is to focus on what's happening among people, not where they are or how many are present. We can say that interpersonal communication is a different kind of interaction between people (Wood, 2016).

Interpersonal communication or interpersonal communication is face-toface communication between people, which allows each participant to capture others' reactions, both verbally and nonverbally directly (Aw, 2011). From this understanding, communication interpersonal can take several keywords, i.e., the first is electives. This means that interpersonal communication is done selectively on the opponent's communication. Then interpersonal communication is also systemic, meaning that it occurs in various systems or contexts that affect what is happening and the meaning in the interaction.

Interpersonal communication is an ongoing and ongoing process. This means; first, communication evolves, becoming more intimate and talking about personal things as people interact (Thurlaw, 2004). Friendships and romantic relationships deepen and matter over time, and their quality can also decline over time. Personal knowledge and insights will grow and develop 
with interpersonal communication. To connect as a unique individual, one must know others personally and understand their thoughts and feelings. As everyone is unique, so is every interpersonal relationship. Each develops different patterns and rhythms and even a specific vocabulary that is not part of other interpersonal relationships.

The essence of interpersonal communication is to share meaning between people. Humans don't just exchange words while communicating. Instead, they create sense when interacting, i.e., figuring out what each word and behavior means, representing what, or implying what. The growing meaning of the history of interaction between people is unique.

In Aw (2011), it is also explained about the purpose of interpersonal communication, among others, expressing attention to others, finding oneself, finding the outside world, building and maintaining harmonious relationships, and influencing attitudes and behaviors. Sometimes, someone does interpersonal communication just looking for fun or entertainment. Talking to friends about birthday celebrations, discussing sports, exchanging funny stories is a conversation to fill in and spend time.

The interpersonal communication discussed in this study relates to communication between two (or more) people in a virtual world setting. Because technology is getting more sophisticated and developed, it certainly impacts the rapid flow of information and the form of community interaction. People now interact more or communicate through cyberspace, meaning interpersonal communication is directly mediated by computers.

\section{Computer-Mediated Interpersonal Communication}

After the industrial revolution 4.0, technology continued to evolve. Almost all human activities now use technology in their work, ranging from education, economics, politics to health. Communication also has a significant influence on the development of technology. Communication can now be done anywhere and anytime with anyone regardless of distance or time. As Dominick (2009) says, modern technology communication makes it easy for everyone to connect 24 hours and seven days a week, so information is easy to get anytime and anywhere. From the development of modern technology, communication was born a new medium. According to Wikipedia, new media is a terminology to describe the convergence between computerized digital communication technologies and networks.

Communication in cyberspace supports interpersonal communication 
from one person to another and can spread messages or information to the public. This happens because the user more directly controls the Internet; the user determines the activities performed, so the interactivity is higher. Interactions that occur also involve asynchronous communication that is not done simultaneously, not face-to-face, and pauses in the feedback. And also involves synchronous communication that happens in real-time, can be done face-to-face via video conference, and the feedback received is immediately felt by the interacting party.

Communication between social media users or interactive media is intimate even if the users do not meet in person. Usually, they are bound by the same interests or likes to form a virtual community. Virtual communities also have a high level of familiarity because they are no longer limited by space and time. Interpersonal communication built-in cyberspace also has a high level of intimacy because although they do not know the user's real identity, they often share life stories.

\section{Social Media}

Social media is a collection of internet-based applications based on the ideology and technology of Web 2.0, thus enabling the creation and exchange of content by its users (Kaplan \& Haenlein, 2010). Social media has very high interactive content due to the discussion of content or information among its users. Users can easily participate directly in interactions on social media. The business itself can be one-to-one or now by many people in a community.

Please note that social media is not online mass media. However, social media can use it to share information with the audience; social media is often used for personal communication by its users through the comments feature or direct messages.

Social media today is very diverse, ranging from Twitter, Facebook, Instagram, and so on. Because of this, social media is increasingly attracting people to use it. And everyone usually uses not just one social media but a few of them. Social media, like everything in the world, certainly has a positive and negative impact. When viewed from the positive impact, with social media, one will be more active and have a lot of social connections, increase social engagement, and continually update with information and phenomena discussed (Khan, et. al., 2013).

Whereas, when viewed from the opposite side, social media has made an insufficient private space and its users' public area. Many do not hesitate to 
provide personal information such as uploading selfies, telling their full names, birthdays, places of residence, etc. Many of them also feel a dependence on social media, so they forget about their lives in the real world and invest more in the sphere of cyberspace. Also, as Ibrahim (2011) stated, the generation that grows up in digital culture tends to be alone (dissociative), so it will lack sympathy for the surrounding environment, which can cause other new problems such as cyber-bullying.

\section{Methods}

The method used in this study is literature study or literature research. Literature research is meant by research conducted only based on written work, including the results of research both that has been and has not been published (Dew, 2012). The required data collection is not obtained by going down directly to the field but obtained from trusted library or document sources. The source consists of a group of other scientific articles published in journals both nationally and internationally, articles from trusted websites, and e-books.

The type of data used in the literature research method is secondary data, i.e., data obtained or collected by people who research available sources. These people do not receive information or data directly from the phenomena discussed but get information or data from other primary sources.

In addition to the literature research method, observation methods and in-depth interviews were also used as complementary elements in this study. Observations are made online by scanning interactions on selected Twitter users. In-depth interviews were conducted on ten Twitter users with high school education backgrounds and following each other. The question emphasizes the origin of using social media to the characteristics of tweets that give rise to personal closeness with other users.

\section{Results And Discussions}

\section{Establishment of Computer-Based Interpersonal Communication}

Interpersonal communication occurs between two (or more) people in which a verbal or nonverbal message exchange occurs, and therefore an intimate relationship is formed. Interpersonal communication is usually done face-to-face. But with the rapid development of technology, interpersonal communication can now be done through computers in the form of social media applications. 
McLuhan (Griffin, 2003) states about the relationship between technology, media, and society or technological determinism, namely the understanding that technology is determinant or decisive in shaping human life. The relationship can interpret that social media has now created a new form of human interpersonal communication, both to family, friends, coworkers, and even strangers.

Ayun's research (2016) stated that interpersonal communication, especially in adolescents, has changed many media. From the traditional meeting in person, they are now using social media to facilitate communication. One of the social media used is Instant Messenger, such as WhatsApp and Line, to exchange text messages between users. Further explained that in conducting communication on social media will be formed internet language. One example of the influence of internet language is the appearance of emotional icons(emoticons) or emojis as a complement in interpersonal communication. These icons appear as a form of user emotion when communicating via instant messenger. This study shows that with emoji to share, making communication through instant messenger more effective than just using text.

Interpersonal communication mediated by the central computer is done in direct messages. No matter what application or social network you use, personal interactions are more common in the direct message section. The user can also determine if he will interact with one or only to be more personal. They are used to interact with other people and create group chats on social media. Interactions that are done alone can start from the same interest in something or the user's background; there are similarities. When interacting on social media, there is no limit to what fellow users are talking about everything.

In Suparno's discovery, et al. (2012) explained that Facebook social media users do not believe what other users say is one hundred percent true. Because there are still many possibilities that a person can hide his identity on the Internet, his nature and character can also be different when interacting on the Internet and when interacting directly. Many of Facebook's social media users also use the app to interact with people they know in general. Through Facebook, for example, they use to ask old friends who have rarely met or invite junior high school friends for a reunion together. But in addition to familiar friends, Facebook users are also open to accepting people they don't already know. As long as these unknown people want to be invited to get acquainted, they also keep an eye on and consider through mutual friends that are friends on Facebook that are the same as them. 
Twitter can form interpersonal communication in computer-mediated communication through social media, mainly done in the network's direct message feature. While it can't entirely run like real-world interpersonal communication face-to-face, interpersonal communication in cyberspace can also build intimate relationships. For example, in a matchmaking app, both participants' interpersonal communication will form personal relationships, even more, private than other relationships in the real world. From here, users of social media accounts can desire to interact directly with their online friends. Therefore, relationships created from interpersonal communication on social media are intimate.

\section{Adolescents and Interpersonal Communication on Social Media Twitter}

Interpersonal communication on social media has its uniqueness. Social media users also have different views on the services provided by each social media. As well as teenagers, 8 out of 10 teenagers interviewed have a particular reason for using social media. They use Instagram when they want to show their existence and upload photos, then switch to Using WhatsApp when there's a need for communication with their classmates and change social media again when they want to get acquainted with new people using Twitter. In comparison, the other two teenagers are more passive in using Twitter.

Twitter is now one of the most used social media by teenagers. The sheer number of features on Twitter's social media makes teens feel interested in using it. In Suparno's study (2012), adolescents judged that from a level of trust and honesty to what is said in it, Twitter is more trustworthy and more honest than Facebook. Users of Twitter accounts among teenagers use social media primarily to seek information because social media is one of the most up-to-date on the phenomenon in public. In addition to finding information, Twitter social media is seen as reliable when making new friends. Many of them found close friends from social media.

Based on researchers' observations, teenagers on Twitter often follow the accounts they like, such as meme accounts, bases, fan accounts, and so on. It is from here that interactions usually begin to form. When something they like, they'll retweet, like, or write a comment under the upload. And from their words, there will be other users who reply to their comments, and this process will continue again and again. From the interaction of these comments then they will follow each other's accounts and become mutual on their Twitter accounts. 
Then there will be more interaction after that, both in the comments field and in the direct message feature.

How interaction can form through intimate relationships on Twitter can be in many ways. But as a result of the researchers' observations, many teenagers like to tweet about personal issues in their lives.

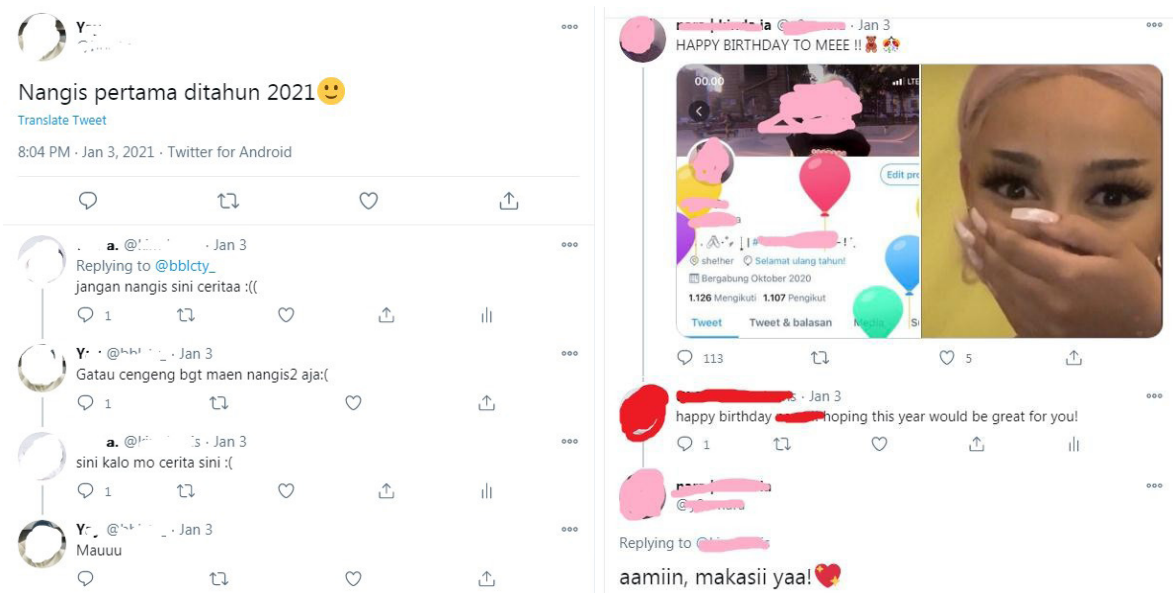

Figure 1. Twitter User Interaction

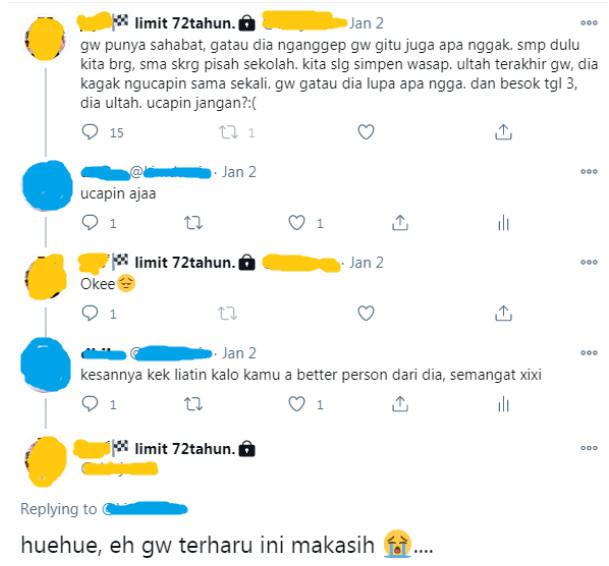

Figure 2. Teen tweets on personal issues

As can be seen in the picture above, teenagers tend to tweet about their problems. Whether it's something that makes him sad (pictures 1 and 3) or personal information like birthdays (figure 2), there will be a familiar feeling 
between the two users from such short interactions. In the case in the first image, the business of the two continues to the direct message. And from there, the communication that takes place feels more personal and more intimate; finally, there will be a strong interpersonal relationship between the two users. Interactions will not occur once but can constantly happen because they already feel close to each other.

\section{Conclusion}

Interactions that occur on social media through computer-mediated communication $(\mathrm{CMC})$ can form an interpersonal relationship between users. Especially among teens on Social Media Twitter, businesses are generally done by commenting on each other's tweets or exchanging messages in the direct message feature. The topics that are often discussed in these interactions are personal, making communication more intimate and making a close relationship between communication participants. But on the condition that among these users have followed each other.

\section{References}

Aw, S. (2011). Komunikasi interpersonal. Graha Ilmu.

Ayun, P. Q. (2016). Penggunaan instant messenger dan komunikasi interpersonal remaja. Jurnal Ilmu Sosial, 15(2), 111-120. https://doi.org/10.14710/ jis.15.2.2016

Ibrahim, S. I. (2011). Kritik budaya komunikasi. Jalasutra.

Jeleel. (2013). Fundamentals of computer studies (pp. 1-59). Expert Solution Consults

Kaplan, A.M., \& Haenlein, M. (2010). Users of the world, unite! Challenges and opportunities of social media. Business Horizons, 53(1), 59-68. https://doi. org/10.1016/j.bushor.2009.09.003

Khan, GF., Swar, B., \& Lee, K. S. (2013). Social media risks and benefits: a public sector perspective. KoreaTECH.

Littlejohn, S., \& Foss, K. (2009). Computer-mediated communication in the encyclopedia of communication theory. SAGE Publications Inc.

Nurhadi, Z. F. (2017). Model komunikasi sosial remaja melalui media Twitter. Journal Aspikom, 3(3), 539. https://doi.org/10.24329/aspikom.v3i3.154 
Pratiwi, F.D. (2014). Computer mediated communication (CMC) dalam perspektif komunikasi lintas budaya (Tinjauan pada Soompi Discussion Forum Empress Ki Tanyang Shipper). Profetik: Jurnal Komunikasi, 7(1), 29-43.

Saleh, G., \& Pitriani, R. (2018). Pengaruh media sosial Instagram dan Whatsapp terhadap pembentukan budaya "Alone Together". Jurnal Komunikasi, 10(2), 103-14. https://doi.org/10.24912/jk.v10i2.2673

Suparno, B. A., Sosiawan, E. A., \& Tripambudi, S. (2014). Computer mediated communication situs jejaring sosial dan identitas diri remaja. Jurnal Ilmu Komunikasi, 10(1), 85-102. https://doi.org/10.31315/jik.v10i1.88

Suryanto. (2015). Pengantar ilmu komunikasi. CV Pustaka Setia

Swing, P. Q. (2016). Use of instant messenger and adolescent interpersonal communication. Journal of Social Sciences, 15(2), 111-120. https://doi. org/10.14710/jis.15.2.2016

Thurlow, C., Lengel, L., \& Tornic, A. (2004). Computer-mediated communication: Social interaction and the internet. SAGE Publications Ltd.

Twitter. (2016). 83\% Pengguna milenium indonesia menganggap twitter sebagai sumber yang dapat dipercaya untuk informasi produk. https://blog.twitter. com/in_id/a/id/2016/83-pengguna-milenium-indonesia-menganggaptwitter-sebagai-sumber-yang-dapat-dipercaya-untuk.html. Accessed 16 Januari 2021.

Wood, A. F., \& Smith, M. J. (2005). Online communication, linking technology, identity $\mathcal{E}$ culture (4th ed). Lawrence Erlbaum Associates Inc.

Wood, J. T. (2016). Interpersonal communication: Everyday encounters (8th ed). Cengage 